\title{
Respiratory Movements of Patients with Severe Chronic Obstructive Lung Disease and Emphysema in Supine and Forward Standing Leaning
}

\author{
Asdis Kristjansdottir ${ }^{1}$, Magdalena Asgeirsdottir ${ }^{1}$, Hans Beck ${ }^{1}$, Petur Hannesson², \\ Maria Ragnarsdottir ${ }^{3}$ \\ ${ }^{1}$ Reykjalundur Rehabilitation Center, Mosfellsbaer, Iceland \\ ${ }^{2}$ Department of Radiology, Landspitali National and University Hospital, Reykjavik, Iceland \\ ${ }^{3}$ Department of Physiotherapy, Landspitali National and University Hospital, Reykjavik, Iceland \\ Email: asdiskri@reykjalundur.is
}

Received 2 January 2015; accepted 19 January 2015; published 26 January 2015

Copyright (C) 2015 by authors and Scientific Research Publishing Inc.

This work is licensed under the Creative Commons Attribution International License (CC BY).

http://creativecommons.org/licenses/by/4.0/

(c) (i) Open Access

\begin{abstract}
Objective: To investigate respiratory movements in supine and forward standing leaning position among patients with emphysema and severe chronic obstructive pulmonary disease (COPD) during rest and dyspnea. Methodology: Nineteen patients with emphysema and severe COPD underwent lung function measurement and positional assessment of diaphragm. Respiratory movements during quiet and deep breathing were measured in supine and standing forward leaning using the Respiratory Movement Measuring Instrument (RMMI) (MTT, Arleyni 8, Reykjavik, Iceland). Patients then bicycled with the work rate $87 \%$ of the peak work rate tolerated in a pre-program incremental exercise test. Immediately after dismounting the bicycle, respiratory movements were measured in forward leaning. Results: For participants with mean age of $61 \pm 7$ years and mean body mass index of $23.59 \pm 4.63$, respiratory movements during quiet breathing in supine were significantly (abdominal $p=0.025$, lower- and upper-thoracic $p=0.020$ ) greater than in forward leaning. In the case forward leaning during dyspnea, lower- and upper-thoracic movements were significantly ( $p=0.001 ; p=0.005$, respectively) less than abdominal. Conclusion: This study indicates that the diaphragm of patients with severe COPD and emphysema is active in forward leaning position during rest and dyspnea.
\end{abstract}

\section{Keywords}

Respiratory Movements, Dyspnea, Pulmonary Rehabilitation

\footnotetext{
${ }^{*}$ Corresponding author.
}

How to cite this paper: Kristjansdottir, A., Asgeirsdottir, M., Beck, H., Hannesson, P. and Ragnarsdottir, M. (2015) Respiratory Movements of Patients with Severe Chronic Obstructive Lung Disease and Emphysema in Supine and Forward Standing Leaning. Open Journal of Respiratory Diseases, 5, 1-9. http://dx.doi.org/10.4236/ojrd.2015.51001 


\section{Introduction}

Pulmonary rehabilitation is one of the cornerstones in modern care of patients with chronic obstructive pulmonary disease (COPD) and emphysema, although it has no direct effect on airflow limitation [1]. However, pulmonary rehabilitation diminishes the systemic effects and co-morbidities of the disease and does so highly effectively as well as cost-effectively [2]. One of the consequences of COPD and emphysema is hyperinflation of the lungs, which means that the resting volume or forced vital capacity, FRC is increased and can exceed tidal volume [3]. Dynamic hyperinflation is the phenomenon when expiration is slowed and interrupted by the next inspiratory effort, i.e. the situation where tidal inspiration begins before expiration is completed [3] [4]. The increased lung volume at rest means that the thorax is expanded from normal resting position and consequently less expansion is available for inspiration. During physical exertion, respiratory frequency increases and the time for emptying the lungs diminishes leading to even more hyperinflation and increased FRC. Dynamic hyperinflation can be diminished by reduction of respiratory rate resulting from exercise training and other treatments such as oxygen, pharmacotherapy, and breathing retraining. This, in turn, unloads the respiration and reduces the sensation of dyspnea [1].

The incentive for conducting this study was the clinical observation that our patients with severe COPD and emphysema all, without exception, adopt the forward leaning position while training endurance on ergometer bicycles. Therefore, we found it interesting to investigate whether type of respiratory movement in forward leaning position differed from that in supine position, which is the resting position with the lowest metabolic rate and presumably the least work of breathing [5]. This knowledge could lead to more informed advice to this patient group.

Although the influence of posture on the sensation of dyspnea among patients with advanced COPD has been known among clinicians for a long time, few studies were found on this subject [6]-[9]. O'Neill and McCarthy studied the effect of posture on dyspnea in standing, sitting erect, sitting leaning forward, supine, right lateral decubitus and left lateral decubitus positions, where the standing position served as reference. All patients in this study complained of dyspnea at rest and practically all found relief in the sitting leaning forward posture, i.e. 83\% with moderate and $96 \%$ with severe COPD, while only $18 \%$ and $13 \%$ respectively found relief in the supine position [6].

The forward leaning position has been found to be associated with a significant reduction in electromyographic (EMG) activity of the scalene and sterno-cleidomastoid muscles, an increase in transdiaphragmatic pressure inspiratory muscle pressure and a significant improvement in thoracoabdominal movements [6]-[9].

Confirmed knowledge about respiratory movement patterns among COPD patients in different positions is important for physiotherapists in order to be able to give proper information and guidance to their patients. The forward leaning position at rest and during respiratory distress is particularly of interest in this respect as no study on upper-, lower-thoracic and abdominal respiratory movements among COPD patients with emphysema in this position and condition was found. In a review article Gosselink stated that: "the forward leaning position has been shown to improve diaphragmatic function and, hence, improve chest wall movement, decrease accessory muscle recruitment and dyspnea and by allowing arm or head support the accessory muscles contribute to inspiration in this position" [10].

We therefore wanted to test two hypotheses:

1) Thoracic respiratory movements are greater in forward leaning position with arms supporting than in supine due to the more favorable recruitment of the thoracic accessory respiratory muscles (the pectorals and anterior serrate).

2) Thoracic respiratory movements in forward leaning position are decreased during respiratory distress due to hyperinflation.

We consequently conducted the present cross-sectional study with the purpose of investigating the effect of supine and forward standing leaning posture with support of the forearms on respiratory movement among patients with emphysema and COPD GOLD 3 and 4. In addition the purpose was to investigate respiratory movements in supine and forward standing leaning position among COPD patients during rest and dyspnea.

\section{Methodology}

In this cross sectional cohort study all consecutive patients admitted to Reykjalundur rehabilitation centre for pulmonary rehabilitation diagnosed with emphysema and COPD GOLD 3 and 4 in stable condition ("defined as 
no change in FEV1 during the preceding three months") [11] were asked to participate in the study until 24 had accepted. The patients were examined by two specialists in pulmonary medicine (HJB and MA) and were excluded if they did not have emphysema, had lung cancer or were unable to follow instructions. All participants gave written informed consent prior to participation. The Data Protection Authority and the Ethical Committee (VSNb110600015/03.01) approved the study protocol. The same radiologist (PH) unaware of the patients' condition evaluated radiographs obtained at the entry to the study to establish the presence of emphysema and to exclude other serious conditions which could influence the outcome such as tumor, atelectasis or infiltration. The position of the diaphragm was assessed as normal if the right hemi diaphragm dome was positioned at the $7^{\text {th }}$ to $8^{\text {th }}$ thoracic vertebral level, somewhat lowered at the $9^{\text {th }}$ to $11^{\text {th }}$ thoracic vertebral level and flattened if the right hemi diaphragm dome was lower than at the $11^{\text {th }}$ thoracic vertebral level [12]. Forced vital capacity, forced expiratory volume in one second, forced expiratory volume in one second/forced vital capacity, total lung capacity, residual volume and functional residual capacity were measured using V-max Encore (VIASYS Healthcare Inc./CareFusion 2004 Sensor Medics Corporation, Yorba Linda California).

\subsection{Respiratory Movements}

Prior to the measurements patients were asked standardized questions regarding diseases or trauma that could adversely affect chest movements such as ankylosing spondylitis, neuro-muscular diseases, chest surgery and trauma. Chest wall and abdominal motion was measured with the Respiratory Movement Measuring Instrument (RMMI, MTT, Arleyni 8, 112 Reykjavik, ICELAND), which is based on 6 infrared sensors connected to a PC computer through an analogue to digital converter. The RMMI measures postero-anterior diameter with a measuring frequency of 21 per second and accuracy is $0.0003 \mathrm{~mm}$ and comes with specially designed software. Measurements using the RMMI have been found valid and reliable [13] [14] and have been used in clinical trials [15]-[20].

Respiratory movements were measured in the supine position with $20^{\circ}$ inclination of the head rest and in the forward $45^{\circ}$ leaning position with support of the forearms. The subjects put on protective glasses before the sensors were turned on. Positioning of the sensors was performed by drawing a vertical line from the medial 1/3 of the clavicle on each side of the thorax to the abdominal wall lateral to the umbilicus. The infrared beams were adjusted to fall on each of these vertical lines including one at the height of the $4^{\text {th }}$ rib, one at the $9^{\text {th }}$ rib, and one lateral to the umbilicus. The sensors were then positioned $10 \mathrm{~cm}$ from these landmarks.

\subsection{Procedures to Measure Chest Wall Excursion}

Patients were specifically instructed to "neither move nor talk during the measurement”. Respiratory movements during quiet- and voluntary deep breathing during 60 seconds were then measured. In both cases the computer program counted respiratory frequency. The instruction to the patients prior to measuring deep breathing was: "when I say breathe deeply now, you breathe in and out as deeply as you can in a slow rhythm and keep doing so until I tell you to breathe normally again".

Following these measurements the patients bicycled on a stationary ergometric bicycle (Monark Ergometer RPE 915) with a working load of given proportion of maximal workload tolerated on the graded exercise test (GXT) performed prior to the rehabilitation period, 33\% during warming up for 5 minutes and $87 \%$ for $3 \mathrm{mi}-$ nutes. Immediately after dismounting the bicycle, the patients resumed the standing forward leaning position and their respiratory movements were measured. Instruction to the patients was: "relax and recover from the exertion”. Dyspnea was measured using 0 - 10 visual-analogue scale at rest and at the end of the exertion [21].

\subsection{Statistical Analysis}

Descriptive statistics were used for all variables. For comparison of respiratory movements in the supine and standing forward leaning position at rest and during respiratory distress Wilcoxon Signed Ranks Test was used as the data were not normally distributed. The SPSS computer program $11^{\text {th }}$ edition was used for calculations.

\section{Results}

Subjects were 8 males and 11 females recruited during the period from December $2^{\text {nd }} 2011$ to September the $28^{\text {th }}$ 2012. Five subjects were excluded, three did not have emphysema, one had lung cancer and one was unable to 
follow verbal instructions during measurements. Socio-demographic data are shown in Table 1.

Nine subjects stopped smoking at the time of entrance to the rehabilitation program. No patient had paradoxical type of breathing (Hoover's sign) at rest, during deep breathing or during distress and nine subjects had a flattened diaphragm, among nine the diaphragm was somewhat lowered and 1 had a diaphragm in normal position. Lung volume and diffusion measurements are presented in Table 2.

\section{Respiratory Movements}

Respiratory movements during quiet breathing in two positions are shown in Figure 1. Data from the right side is used in all graphs as movements in all positions and respiratory mode were symmetrical. Average respiratory frequency in the supine position was $15.8 \pm 3.5$ and in the forward leaning position $13.7 \pm 4.9$. The difference was not significant $(\mathrm{p}=0.18)$.

During voluntary deep breathing in the supine position (Figure 2) thoracic movements were more dominant than abdominal movement although the difference was not significant. In forward leaning position upper thoracic movement was significantly less than in supine position $(p=0.03)$. Type of respiratory movement changed from thoracic dominant in the supine position to more even distribution in the forward leaning position, where abdominal movement was slightly increased and thoracic movement decreased compared to the supine position. Average respiratory frequency during voluntary deep breathing in the supine position was $7.4 \pm 4.0$ and in the forward leaning position $7.9 \pm 4.7$ ( $\mathrm{p}=0.27$ ). Respiratory movements during voluntary deep breathing in the supine and standing forward leaning position are shown in Figure 2.

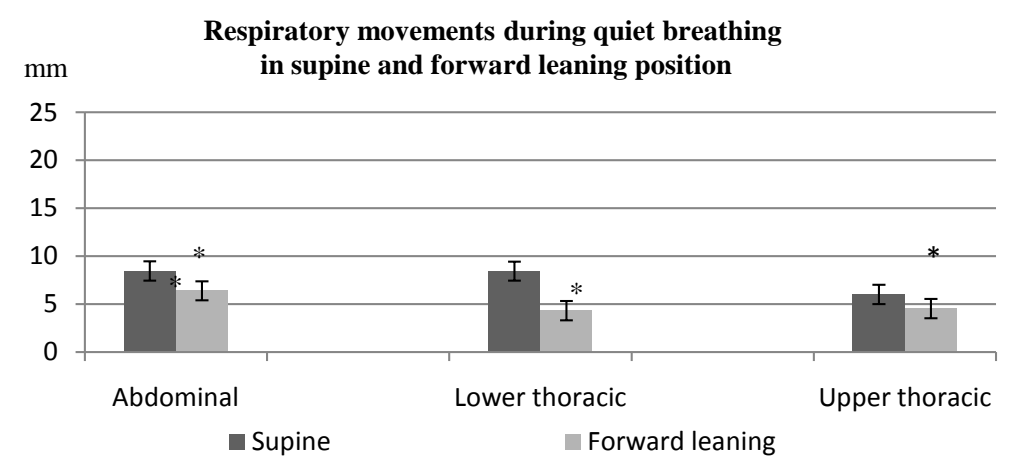

Figure 1. Respiratory movements during quiet breathing in the supine and standing forward leaning position. ${ }^{*} \mathrm{p}=\leq 0.025$.

Table 1. Socio-demographic data.

\begin{tabular}{cccccc} 
& $\mathrm{n}=19$ & $\mathrm{n}=19$ & $\mathrm{n}=10$ & $\mathrm{n}=6$ & $\mathrm{n}=6$ \\
$\mathrm{Bge}$ in years & $\mathrm{BMI} \mathrm{kg} / \mathrm{m}^{2}$ & Stop smoking in years & $\begin{array}{c}\mathrm{O}_{2} \text { in liter } \\
\text { Dyspnoea at rest Borg 0 - 10 }\end{array}$ & 2.5 & $1.75 \pm 0.71$ \\
Mean \pm StDev & $61 \pm 7$ & $23.59 \pm 4.63$ & $3.5 \pm 2.76$ & $0.5-11$ & $1-3$ \\
\hline
\end{tabular}

StDev = standard deviation; $\mathrm{BMI}=$ body mass index; $\mathrm{O}_{2}$ = additional oxygen.

Table 2. Lung volume and diffusion measurements.

\begin{tabular}{cccccccc}
\hline & $\begin{array}{c}\text { FVC \% } \\
\text { predicted }\end{array}$ & $\begin{array}{c}\text { FEV }_{\mathbf{1}} \text { \% } \\
\text { predicted }\end{array}$ & $\begin{array}{c}\text { FEV }_{\mathbf{1}} \text { \% \% } \\
\text { predicted }\end{array}$ & $\begin{array}{c}\text { TLC \% } \\
\text { predicted }\end{array}$ & $\begin{array}{c}\text { RV \% } \\
\text { predicted }\end{array}$ & $\begin{array}{c}\text { FRC \% } \\
\text { predicted }\end{array}$ & $\begin{array}{c}\text { DLCO \% } \\
\text { predicted }\end{array}$ \\
\hline Mean & 79.95 & 35.37 & 47.74 & 102.33 & 130.60 & 117.47 \\
StDev & 13.43 & 7.57 & 6.85 & 17.90 & 41.41 & 31.26 & 10.27 \\
Range & $51-112$ & $26-50$ & $36-59$ & $70-136$ & $81-221$ & $68-176$ \\
\hline
\end{tabular}

FVC = forced vital capacity; $\%$ predicted $=$ percent of predicted values; FEV1 = forced expiratory volume in one second; FEV $\%=$ forced expiratory volume in one second as percent of forced vital capacity; $\mathrm{FEV}_{1} \% \%$ predicted = percent predicted of forced expiratory volume in one second as percent of forced vital capacity; TLC = total lung capacity; RV = residual volume; FRC = functional residual capacity; DLCO = diffusing capacity. 


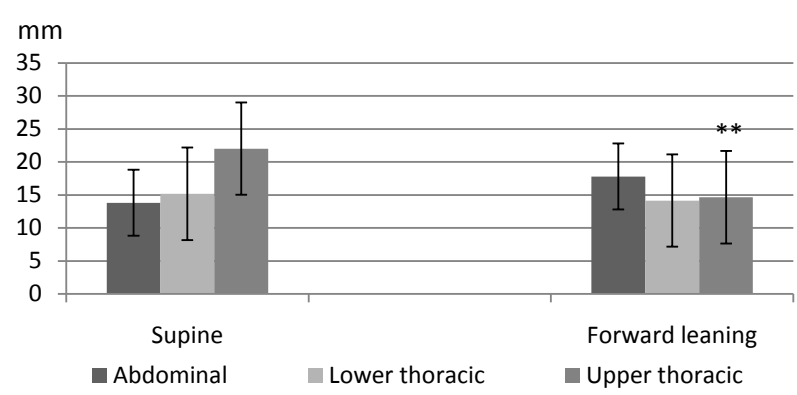

Figure 2. Respiratory movements during voluntary deep breathing in supine and forward leaning positions. ${ }^{* *} \mathrm{p}=0.03$.

Table 3 shows the results of bicycling to evoke respiratory distress.

Lower- and upper-thoracic movements were significantly less ( $p=0.01$ and $p=0.05$ respectively $)$ than abdominal movements in the forward leaning position immediately after physical exertion (Figure 3). The figure also demonstrates the same type of respiratory movement during quiet breathing and distress in this position.

Respiratory movements in the standing forward leaning position show the same type of respiratory movements at rest and during respiratory distress (dyspnea).

\section{Discussion}

The novel result from this study is the effect of the forward leaning position with support of the forearms on respiratory movements during respiratory distress, where abdominal movements were dominant and lower- and upper thoracic movements were significantly ( $\mathrm{p}=0.01$ and $\mathrm{p}=0.05$ respectively) less than abdominal movements. This is in favor of our hypothesis two, which suggested decreased thoracic movements during respiratory distress due to hyperinflation, placing the chest wall in near maximal expansion at functional residual capacity and thus leaving small range of motion left for respiratory movement. No studies were found measuring abdominal-, lower- and upper-thoracic respiratory movements in the forward leaning position immediately after physical exertion. Reports on dyspneic patients with moderate and severe COPD in the seated forward leaning position demonstrate that diaphragmatic pressure is greater in this position than in supine, standing or seated erect positions and is preferred for reduction of dyspnea by majority of patients [6] [7].

It is interesting to note that type of respiratory movement in forward leaning position is the same at rest and during respiratory distress (Figure 3). During voluntary deep breathing in forward leaning position the range of motion is almost the same at all three measuring sites.

During measurements of voluntary deep breathing the instruction to the patients was to breath as deeply as possible and in a slow rhythm, enabling them to exhale more volume air than they do in distress. This could explain the greater thoracic movements during voluntary deep breathing than during respiratory distress and excludes the possibility of decreased range of motion as explaining factor for decreased movement in respiratory distress. But since type of respiratory movement was the same during distress and at rest, another explanation of reduced thoracic movement during distress could be the different neural pathways used for spontaneous and voluntary breathing [22] [23], where spontaneous breathing favors the diaphragm but during voluntary breathing thoracic and abdominal movement are activated equally. The third factor to take into consideration is the gender difference in voluntary deep breathing as men maintain abdominal type of breathing but women show nearly equal ranges of movement for all three measuring sites and 58\% of our subjects were women [18].

Researchers have found that type of respiratory movement during quiet breathing in the supine position is not different among patients with severe COPD from non-symptomatic individuals [24] [25]. Our subjects showed the same type of respiratory movement in the supine position as in those studies.

The general belief has been that thoracic respiratory movements increase in forward leaning position with fixed arms due to increased activity of the accessory respiratory muscles [10]. Our results do not support that notion as lower- and upper-thoracic movements were significantly ( $p=0.02 ; \mathrm{p}=0.02$, respectively) less in forward leaning position than in supine position during quiet breathing and upper thoracic during voluntary deep breathing $(\mathrm{p}=0.03)$. We therefore reject our first hypothesis. Other investigators using EMG and gastric pressure measurement have found increased diaphragm activity in forward leaning position and suggest that diaph- 


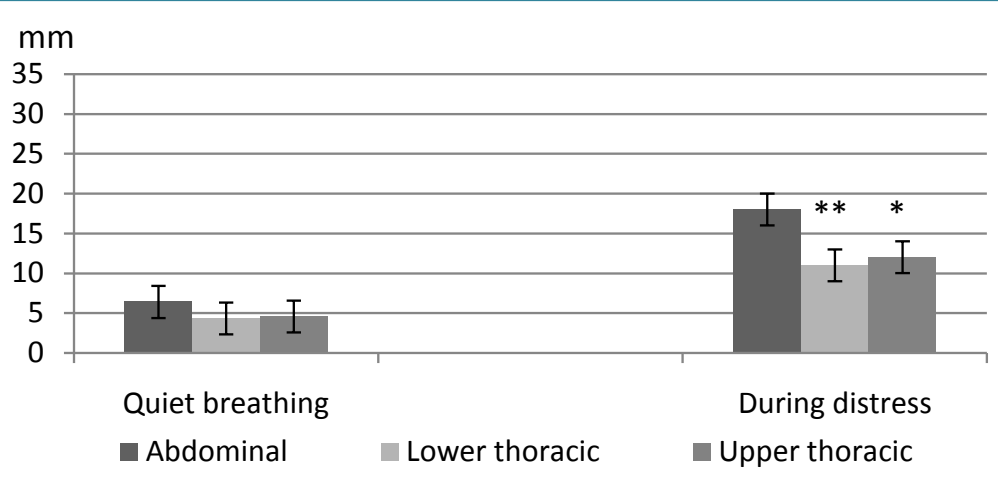

Figure 3. Respiratory movements in the standing forward leaning position at rest and during respiratory distress. ${ }^{* *} \mathrm{p} \geq 0.01,{ }^{*} \mathrm{p} \geq 0.05$.

Table 3. Data from bicycling with the purpose of generating respiratory distress.

\begin{tabular}{ccccccccccc}
\hline & Warm up & \multicolumn{3}{c}{ Dyspnoea } & \multicolumn{3}{c}{ Work load } & \multicolumn{3}{c}{ Dyspnoea } \\
& Watts & $\mathrm{HR}$ & $\mathrm{SO}_{2}$ & $\mathrm{Borg}$ & Watts & $\% \mathrm{GXT}$ & $\mathrm{HR}$ & $\mathrm{SO}_{2}$ & Borg $^{2}$ \\
\hline Mean & 21.05 & 90 & 95.47 & 0.95 & 53.68 & 87.2 & 116 & 92 & 5.5 \\
StDev & 8.57 & 13.66 & 2.04 & 1.13 & 21.14 & 11.04 & 17 & 2.48 & 0.96 \\
Range & $15-45$ & $70-117$ & $92-98$ & $0-3$ & $25-105$ & $70-109$ & $88-139$ & $88-96$ & $4-7$ \\
\hline
\end{tabular}

$\mathrm{Hr}=$ heart rate; $\mathrm{SO}_{2}=$ oxygen saturation; $\mathrm{GXT}=$ grated exercise test.

ragm muscle contraction could be more effective in generating movement in this position due to more favorable length-tension state of the muscle [4]. They also found that EMG signals from neck and accessory respiratory muscles in seated forward leaning positions showed decreased EMG activity from erect sitting or supine position and suggested that the muscles could generate more movement with the same amount of muscle recruitment [4]. In view of our results the reason for less EMG activity is more likely to be less movement. Bhatt et al. on the other hand, proposed that, with fixed arms the accessory muscles will splint the upper chest wall and thereby improve diaphragmatic function, which is more in line with our results [26]. We suggest that these results indicate that the patients use this position to obtain less energy demanding breathing. The fact that respiratory frequency is not increased in forward leaning position, but rather a little less during quiet breathing than in the supine position, further supports our suggestion.

During voluntary deep breathing, type of respiratory movement in supine position was the opposite from what was expected and from that among non-symptomatic men, where abdominal movement is dominant. Non symptomatic women, however, show almost equal excursion of diaphragmatic and thoracic movements [18]. In forward leaning position type of movement was also opposite to what was expected as the diaphragm showed the greatest excursion. The different excursion of the diaphragm in the two positions has been explained by its location in the thoracic cavity and its ability to contract in each position. This is somewhat surprising as the diaphragm has been thought to be of limited use when its position is as low in the thoracic cavity as among approximately half of our patients, as 9 subjects had flattened diaphragm, among 9 the diaphragm was somewhat lowered and only 1 subject had normal position of the diaphragm. The difference in excursion of the lower- and upper-thorax is more difficult to explain as the instructions to the patients were to breathe as deeply as they can in a slow rhythm.

A pilot study on voluntary deep breathing in forward leaning position among 10 non symptomatic women (unpublished data from MR) (Figure 4) showed type of respiratory movement which was in keeping with the general belief that thoracic movements were increased compared to respiratory movements in supine position. Our hypothesis was that the same would be the case among COPD patients, but although measured in the same position and same respiratory mode with the same instrument, the type of movement turned out to be quite opposite. The reason for this is difficult to explain as the diaphragm has the same advantages regarding its position within the thorax for both groups and hyperinflation can hardly be the only factor explaining less thoracic movement among the patients. 


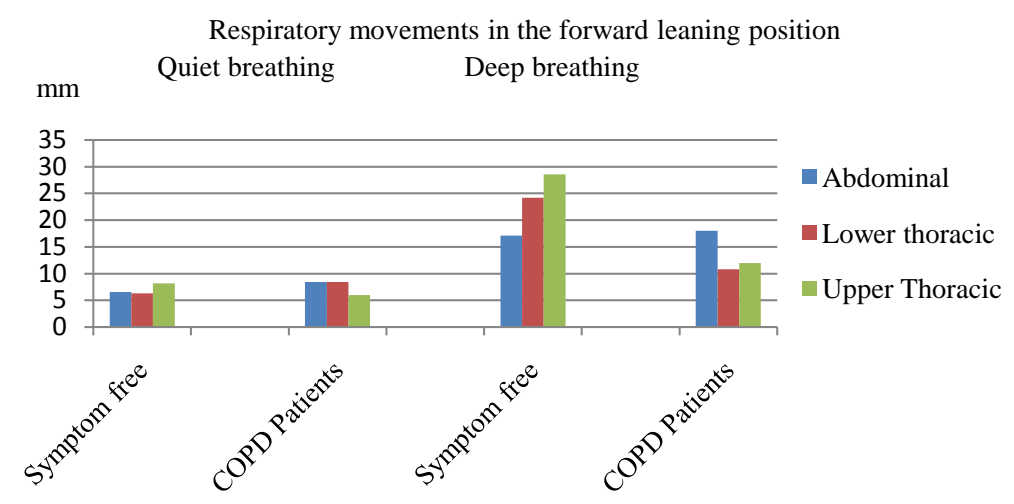

Figure 4. Respiratory movement in the forward leaning position among symptom free individuals and patients with COPD.

\section{Limitations of the Study}

The limitations of the study are mainly a small sample size and the lack of gender matched non-symptomatic subjects as there is a gender difference in type of breathing during voluntary deep breathing in a symptom free population. Another limitation is the combined subject group of GOLD 3 and 4 COPD patients. As we were not able to find any plausible explanation why respiratory movements in the forward leaning position were less than in the supine position we asked one of our subjects why she used this position and her answer was: "because it opens up for my breathing and I am able to breathe more deeply and slower"; "the dyspnea decreases more rapidly when I use this position”. Further research is needed to investigate the scientific explanation for this finding. Future research is planned to demonstrate the activity of the diaphragm in the forward leaning position with ultrasound and tidal volume measurements.

\section{Clinical Relevance and Further Studies}

This study indicates that forward leaning position with support of the forearms is a favorable resting position for severe COPD and emphysema patients. Furthermore, instead of Nordic walking, walking with incremental forward leaning is worth trying.

Further study with greater sample size is needed. Investigating inspiratory muscle training in forward leaning position among this patient group is of interest.

\section{Conclusions}

Hypothesis 1 stated that thoracic respiratory movements are greater in forward leaning position with arms supporting than in supine due to the more favorable recruitment of the thoracic accessory respiratory muscles (the pectorals and anterior serrate). We reject this hypothesis as respiratory movements in forward leaning position were less than in supine position during quiet breathing. This could explain why our COPD patients with emphysema and GOLD 3 and 4 use this position while bicycling.

Hypothesis 2 stated that thoracic respiratory movements in the forward leaning position are decreased during respiratory distress due to hyperinflation. Our results support this hypothesis as lower- and upper-respiratory movements were significantly less than abdominal movements in forward leaning position during respiratory distress. However, the thoracic respiratory movements during voluntary deep breathing are greater than during distress, indicating that the reason for less movement during distress is not restriction in range of motion.

\section{Acknowledgements}

We thank Arna E. Karlsdottir, physiotherapist and Gudrun Bjarnadottir, laboratory technician for performing all lung volume measurements.

\section{References}

[1] Nici, L., Raskin, J., Rochester, C.L., Bourbeau, J.C., Carlin, B.W., Casaburi, R., et al. (2009) Pulmonary Rehabilitation: 
What We Know and What We Need to Know. Journal of Cardiopulmonary Rehabilitation and Prevention, 29, 141151. http://dx.doi.org/10.1097/HCR.0b013e3181a3324a

[2] Griffiths, T.L., Burr, M.L., Campbell, I.A., Lewis-Jenkins, V., Mullins, J., Shiels, K., et al. (2000) Results at 1 Year of Outpatient Multidisciplinary Pulmonary Rehabilitation: A Randomised Controlled Trial. Lancet, 355, 362-368. http://dx.doi.org/10.1016/S0140-6736(99)07042-7

[3] Gibson, G.J. (1996) Pulmonary Hyperinflation: A Clinical Overview. European Respiratory Journal, 9, $2640-2649$. http://dx.doi.org/10.1183/09031936.96.09122640

[4] Blanch, L., Bernabé, F. and Lucangelo, U. (2005) Measurement of Air Trapping, Intrinsic Positive End-Expiratory Pressure, and Dynamic Hyperinflation in Mechanically Ventilated Patients. Respiratory Care, 50, 110-124.

[5] Rubini, A., Paoli, A. and Parmagnani, A. (2012) Body Meatabolic Rate and Electromyographic Activities of Antigravitational Muscles in Supine and Standing Postures. European Journal of Applied Physiology, 112, 2045-2050. http://dx.doi.org/10.1007/s00421-011-2180-0

[6] O’Neill, S. and McCarthy, D. (1983) Postural Relief of Dyspnoea in Severe Chronic Airflow Limitation. Thorax, 38, 595-600. http://dx.doi.org/10.1136/thx.38.8.595

[7] Sharp, J.T., Druz, W.S., Moisan, T., Foster, J. and Machnach, W. (1980) Postural Relief of Dyspnoea in Severe Chronic Obstructive Pulmonary Disease. American Review of Respiratory Disease, 122, 201-211.

[8] Druz, W.S. and Sharp, J.T. (1982) Electrical and Mechanical Activity of the Diaphragm Accompanying Body Position in Severe Chronic Obstructive Pulmonary Disease. American Review of Respiratory Disease, 125, 275-280.

[9] Delgado, H.R., Braun, S.R., Skatrud, J.B., Reddan, W.G. and Pegelow, D.F. (1982) Chest Wall and Abdominal Motion during Exercise in Patients with Chronic Obstructive Pulmonary Disease. American Review of Respiratory Disease, 126, 200-205.

[10] Gosselink, R. (2003) Controlled Breathing in Patients with Chronic Obstructive Pulmonary Disease [COPD]. Journal of Rehabilitation Research and Development, 40, 25-34. http://dx.doi.org/10.1682/JRRD.2003.10.0025

[11] Heijdra, Y. (1994) Effects of Body Position, Hyperinflation, and Blood Gas Tensions on Maximal Respiratory Pressures with Chronic Obstructive Pulmonary Disease. Thorax, 49, 453-458. http://dx.doi.org/10.1136/thx.49.5.453

[12] Suwatanapongeched, T., Gierada, D.S., Slone, R.M., Pilgram, T.K. and Tuteur, P.G. (2003) Variation in Diaphragm Position and Shape in Adults with Normal Pulmonary Function. Chest, 123, 2019-2027. http://dx.doi.org/10.1378/chest.123.6.2019

[13] Gunnerson, I.L. and Olsén, M.F. (2011) Validity in Measuring Breathing Movements with the Respiratory Movement Measuring Instrument. Clinical Physiology and Functional Imaging, 31, 1-4. http://dx.doi.org/10.1111/j.1475-097X.2010.00970.x

[14] Fagevik Olsén, M. and Romberg, K. (2010) Reliability of the Respiratory Movement Measuring Instrument, RMMI. Clinical Physiology and Functional Imaging, 30, 349-353.

[15] Ragnarsdóttir, M., Kristjánsdóttir, Á., Ingvarsdóttir, I., Hannesson, P., Torfason, B. and Cahalin, L. (2004) Short-Term Changes in Pulmonary Function and Respiratory Movements after Cardiac Surgery via Median Sternotomy. Scandinavian Cardiovascular Journal, 38, 46-52. http://dx.doi.org/10.1080/14017430310016658

[16] Kristjánsdóttir, Á., Ragnarsdóttir, M., Hannesson, P., Beck, H. and Torfason, B. (2004) Respiratory Movements Are Altered Three Months and One Year Following Cardiac Surgery. Scandinavian Cardiovascular Journal, 38, 98-103. http://dx.doi.org/10.1080/14017430410028492

[17] Kristjánsdóttir, Á., Ragnarsdóttir, M., Hannesson, P., Beck, H. and Torfason, B. (2004) Chest Wall Motion and Pulmonary Function Are More Diminished Following Cardiac Surgery When the Internal Mammary Artery Retractor Is Used. Scandinavian Cardiovascular Journal, 38, 1-6. http://dx.doi.org/10.1080/14017430410016396

[18] Ragnarsdottir, M. and Kristinsdottir, E.K. (2006) Breathing Movements and Breathing Patterns among Healthy Men and Women 20 - 69 Years of Age. Respiration, 73, 48-54. http://dx.doi.org/10.1159/000087456

[19] Ragnarsdottir, M., Malmberg, E., Strandberg, E. and Indridason, O. (2011) Increased Physical Fitness among Patients Following Endurance Training during Haemodialysis. Scandinavian Journal of Urology and Nephrology, 46, 54-57.

[20] Fagevik Olsén, M., Pazooki, D. and Granhed, H. (2013) Recovery after Stabilising Surgery for “Flail Chest”. European Journal of Trauma and Emergency Surgery, 39, 501-506. http://dx.doi.org/10.1007/s00068-013-0293-3

[21] Borg, G. (1982) Psychophysical Bases of Perceived Exertion. Medicine Science in Sports Exercise, 14, 377-381. http://dx.doi.org/10.1249/00005768-198205000-00012

[22] Rochester, C.L. and Mohsenin, V. (2002) Respiratory Complications of Stroke. Seminars in Respiratory and Critical Care Medicine, 23, 248-260. http://dx.doi.org/10.1055/s-2002-33033

[23] Ropper, A.H. and Brown, R.H. (2005) Adams \& Victors Principles of Neurology. 8th Edition, McGraw-Hill, New York. 
[24] Gorman, R., McKenzie, D., Pride, N., Tolman, J. and Gandevia, S. (2002) Diaphragm Length during Tidal Breathing in Patients with Chronic Obstructive Pulmonary Disease. American Journal of Respiratory and Critical Care Medicine, 166, 1461-1469. http://dx.doi.org/10.1164/rccm.200111-087OC

[25] Kleinman, B., Frey, K., VanDuren, M., Sheikh, T., DiPinto, D., Mason, R., et al. (2002) Motion of the Diaphragm in Patients with Chronic Obstructive Pulmonary Disease While Spontaneously Breathing versus during Positive Pressure Breathing after Anaesthesia and Neuromuscular Blockage. Anaesthesiology, 97, 298-305. http://dx.doi.org/10.1097/00000542-200208000-00003

[26] Bhatt, S., Guleria, R., Luqman-Arafath, T., Gupta, A., Mohan, A., Nanda, S., et al. (2009) Effect of Tripod Position on Objective Parameters of Respiratory Function in Stable Chronic Obstructive Pulmonary Disease. Indian Journal of Chest Disease and Allied Science, 51, 83-85. 
Scientific Research Publishing (SCIRP) is one of the largest Open Access journal publishers. It is currently publishing more than 200 open access, online, peer-reviewed journals covering a wide range of academic disciplines. SCIRP serves the worldwide academic communities and contributes to the progress and application of science with its publication.

Other selected journals from SCIRP are listed as below. Submit your manuscript to us via either submit@scirp.org or Online Submission Portal.
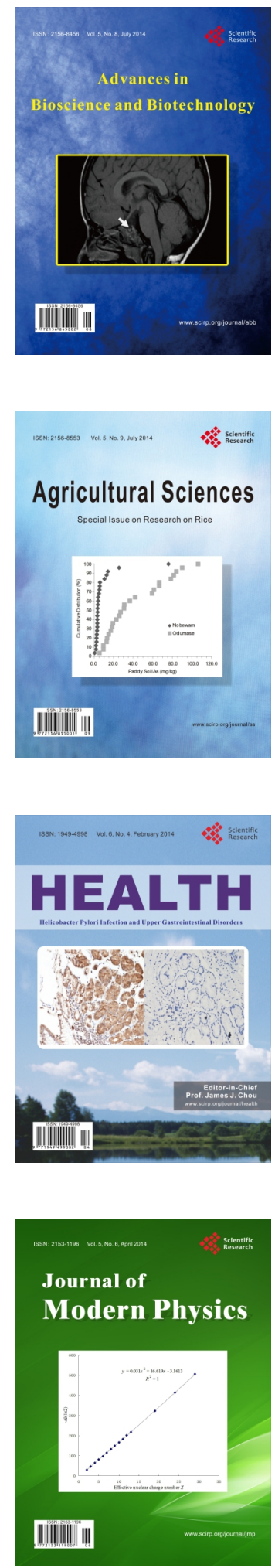
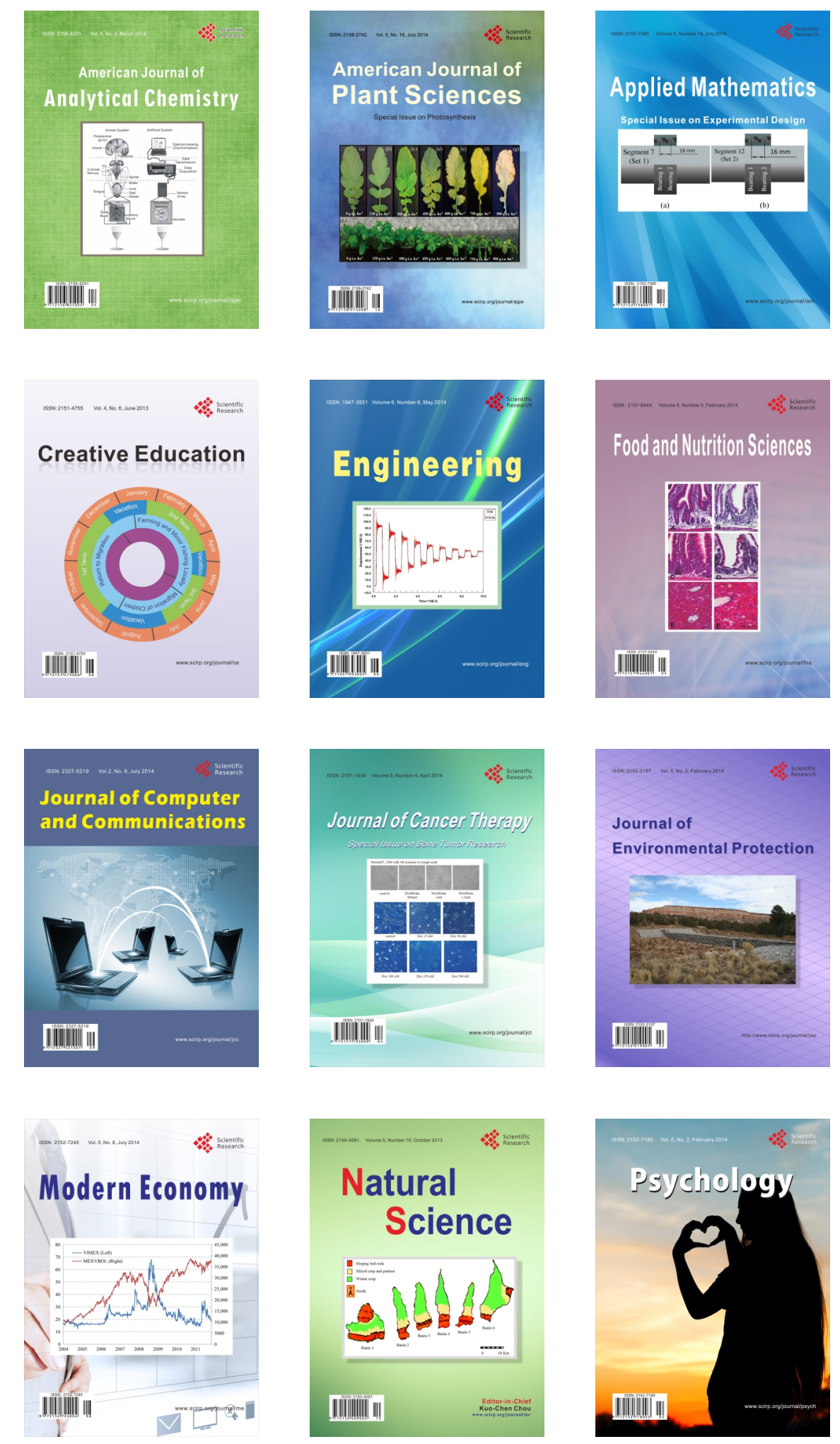